\title{
Characteristics of surface currents in Manado Bay, North Sulawesi, Indonesia
}

\author{
Aulia Dyan Yohanlis*1,2, Mutiara Rachmat Putri1,2,3 \\ ${ }^{1}$ Korea-Indonesia Marine Technology Cooperation Research Center, Cirebon, Indonesia \\ ${ }^{2}$ Earth Science Master Program, Faculty of Earth Sciences and Technology, Bandung Institute of Technology, \\ Indonesia \\ ${ }^{3}$ Research Group of Oceanography, Bandung Institute of Technology, Indonesia
}

*Corresponding author: auliadyanyohanlis@students.itb.ac.id

\begin{abstract}
Manado Bay is a complex waterway located in Manado City, North Sulawesi, Indonesia. It is an entry point for the Indonesia Trough-Flow, and its circulation is affected by the seasonal winds. Manado City has no debris net on its river estuaries. Therefore, marine debris can easily be carried away by the ocean currents and accumulate in the tourism areas located along the coast of Manado Bay. Consequently, it is important to study the sea surface current circulation in Manado Bay to deal with marine debris accumulation. In the present study, we utilized the DELFT3D software to simulate the hydrodynamic circulation in Manado Bay from 2016-2017. We conducted a 2-dimension (2D) horizontal hydrodynamic simulation using tidal and wind forcing from European Centre for Medium-Range Weather (ECMWF). The simulation results indicate that the change in bathymetry and wind affect the sea surface currents. During the summer monsoon (June-August), the sea surface current flows from the northeast to the southwest with an average speed of $1.1 \mathrm{~cm} \mathrm{~s}^{-1}$. On the contrary, during the transitional monsoon 1 (September-November), the sea surface current flows from the southeast to the northwest with an average speed of $1.3 \mathrm{~cm} \mathrm{~s}^{-1}$. Meanwhile, in the winter monsoon (December-February), the sea surface current originated from the southwest flows to the east with an average velocity of $1.9 \mathrm{~cm} \mathrm{~s}^{-1}$. Then, it moves from west to east during transitional monsoon 2 (March-May) with an average speed of $1.5 \mathrm{~cm} \mathrm{~s}^{-1}$. The current speed increases whenthe water enters the strait between the Bunaken Islands due to refraction, diffraction, and shallowing effect. As current flows toward the shallower area, the current speed increases, compensating the water column reduction.
\end{abstract}

Keywords: Sea surface current, Monsoonal Wind, DELFT3D, Manado Bay.

\section{Introduction}

Manado Bay plays an important role as human settlement, as well as for tourism and other economic-related activities. Oceanographic information such as sea surface current is essensial for coastal water management and surveillance. The sea surface current affects the distribution of particular objects or substances in the waters. For example, the sea surface current moves pollutant materials such as plastic bottles accumulating in one place or spreading out in an area by following the current pattern (Kalangi, 2000).

Various physical factors influence the sea surface current, such as wind and tides (Geyer, 1997; Lewis, 1997). Wind pattern in Indonesia is affected by seasonal monsoons, which are the 'summer monsoon' (June-August), 'transitional monsoon' 1 (September-November), 'winter monsoon' (December-February), and 'transitional monsoon' 2 (March-May). The wind transfers its energy to the water surface and contributes to about $2 \%$ of surface current velocity (Knauss, 1977). In the northern hemisphere, the Coriolis effect deflects the direction of surface current to the right of wind direction. Furthermore, the change in monsoonal wind direction and speed cause changes in water current.
In addition to the wind, the tidal cycle also influences the sea surface current. The tidal type in Manado Bay is mixed semidiurnal, which consists of two floods and two ebb tides per day. The current condition is also affected by the two-time tides ranges: during the spring and neap tides. During spring tides, the tidal range reaches its maximum value. In contrast, the neap tide condition develops when the tidal range has a minimum value from the mean sea level.

According to the reasons above, we aim to study the sea surface current circulation in Manado Bay. In the present study, we focus on the sea surface current circulation in 4 different seasons. The model simulates the sea surface current circulation in one tidal cycle at spring and neap tides for each season. Numerical modeling is chosen to reduce the cost and time consuming on complex current seas study.

\section{Materials and Methods}

\section{Numerical Modelling}

We conducted a horizontal 2D (2-dimensions) hydrodynamic simulation using DELFT3D-FLOW software. DELFT3D-FLOW is a software from Deltares to perform 
multi-dimensional (2D and 3D) hydrodynamic simulations. The program calculates current flow at each grid as the result of tidal and wind changes. For the simulation in Manado Bay, we used a rectangular grid that assumed the grid is orthogonal and well-structured in spherical forms.
We then plotted the simulation results using DELFT3DQUICKPLOT integrated with MATLAB.

Two equations were used in DELFT3D-FLOW, which were the momentum and continuity equations, as:

$$
\frac{\partial \zeta}{\partial t}+\frac{1}{R^{2} \cos \phi} \frac{\partial(U R(d+\zeta))}{\partial \lambda}+\frac{1}{R^{2} \cos \phi} \frac{\partial(V R \cos \phi(d+\zeta))}{\partial \phi}=0
$$

with:

$$
\begin{aligned}
& U=\frac{1}{(d+\zeta)} \int_{d}^{\zeta} u d z=\int_{-1}^{0} u d \sigma \\
& V=\frac{1}{(d+\zeta)} \int_{d}^{\zeta} v d z=\int_{-1}^{0} v d \sigma
\end{aligned}
$$

The above DELFT3D-FLOW momentum equations were averaged vertically over the water column as shown in Equations 4-5:

$$
\begin{aligned}
& \frac{\partial u}{\partial t}+\frac{u}{R \cos \phi} \frac{\partial u}{\partial \lambda}+\frac{v}{R} \frac{\partial u}{\partial \phi}-\frac{v^{2}}{R^{2} \cos \phi} \frac{\partial R}{\partial \lambda}+\frac{u v}{R^{2} \cos \phi} \frac{\partial(R \cos \phi)}{\partial \phi}-f v=-\frac{1}{R \cos \phi \rho_{0}} P_{\lambda}+F_{\lambda}+\frac{1}{(d+\zeta)^{2}} \frac{\partial}{\partial \sigma}\left(v_{V} \frac{\partial u}{\partial \sigma}\right)+M_{\lambda} \\
& \frac{\partial v}{\partial t}+\frac{u}{R \cos \phi} \frac{\partial v}{\partial \lambda}+\frac{v}{R} \frac{\partial v}{\partial \phi}+\frac{u v}{R^{2} \cos \phi} \frac{\partial(R)}{\partial \lambda}-\frac{u^{2}}{R^{2} \cos \phi} \frac{\partial(R \cos \phi)}{\partial \phi}+f u=-\frac{1}{R \cos \phi \rho_{0}} P_{\phi}+F_{\phi}+\frac{1}{(d+\zeta)^{2}} \frac{\partial}{\partial \sigma}\left(v_{V} \frac{\partial v}{\partial \sigma}\right)+M_{\phi}
\end{aligned}
$$

where,

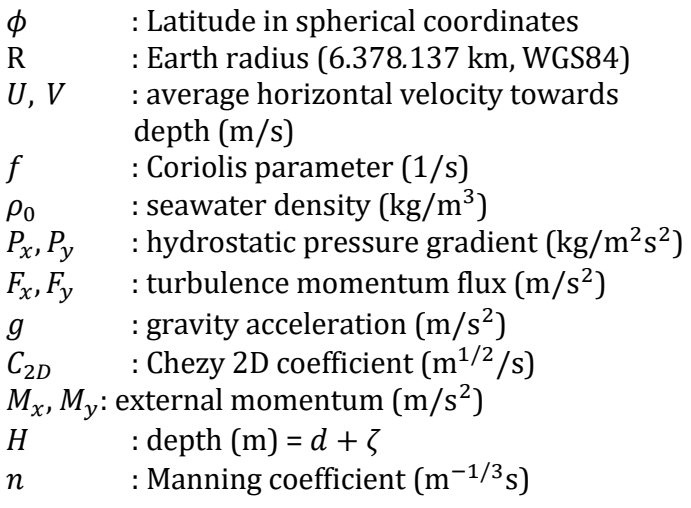

Equation (1) is a mass conservation equation that applies to incompressible fluids averaged against the boundary conditions depths on the surface and at the bottom. The law of conservation of mass states that mass can neither be created nor destroyed. The volume occupied by the matter may change, and the matter density within the system may also be change, but the mass remains constant.
Equations (2) and (3) are the respective velocities integration in the $\lambda$ and $\phi$ directions which are integrated with the depth or transport velocity in $\lambda$ and $\phi$ directions.

Equations (4) and (5) are the momentum conservation equations in the direction $\lambda$ and $\phi$, respectively. In Equations (4) and (5), the density variation is neglected (barotropic waters). The equations on the left side are the local acceleration, convective acceleration, and the Coriolis factor influenced by latitude. The term on the right in Equations (4) and (5) contains the gradient for hydrostatic pressure, turbulence, eddy viscosity, and other momentum forces.

The input data required for the simulation are shoreline, bathymetry, wind, and tidal data, as described in Table 1. 
Table 1. Input data for the simulation.

\begin{tabular}{|c|c|c|c|}
\hline Parameter & Source & Time & Resolution \\
\hline Coastline Data & $\begin{array}{l}\text { https://tanahair.indonesia. } \\
\text { go.id/ }\end{array}$ & - & RBI map 1:25.000 \\
\hline Wind data & https://www.ecmwf.int/ & July 2016 - May 2017 & $\begin{array}{l}u \text { (zonal) and } v \\
\text { (meridional) wind } \\
\text { components at } 10 \mathrm{~m} \\
\text { altitudes. The spatial } \\
\text { resolution is } 0.125^{\circ} \mathrm{x} \\
0.125^{\circ} \text {, while the } \\
\text { temporal resolution is } 6 \\
\text { hours. }\end{array}$ \\
\hline $\begin{array}{l}\text { Bathymetry } \\
\text { data }\end{array}$ & $\begin{array}{l}\text { http://tides.big.go.id/DEM } \\
\text { NAS/Batnas.php }\end{array}$ & - & $\begin{array}{l}\text { The spatial resolution is } 6 \\
\text { seconds or } 185 \mathrm{~m} \text {. }\end{array}$ \\
\hline $\begin{array}{l}\text { Tidal Data } \\
\text { Components }\end{array}$ & TMD (Tidal Model Driver) & $\begin{array}{l}\text { July } 2016 \text { (summer monsoon) } \\
\text { October } 2016 \text { (transitional } \\
\text { monsoon 1) } \\
\text { January } 2017 \text { (winter monsoon) } \\
\text { April } 2017 \text { (transitional } \\
\text { monsoon 2) }\end{array}$ & $\begin{array}{l}\text { Tidal component data } \\
\text { with the TOPEX / } \\
\text { POSEIDON satellite } \\
\text { approach (Tidal Model } \\
\text { Driver) with a spatial } \\
\text { resolution of } 0.25^{\circ} \times 0.25^{\circ} \text {. }\end{array}$ \\
\hline
\end{tabular}

\section{Bathymetry Data}

The bathymetry data is retrieved from the National Bathymetry data (BATNAS) with a spatial resolution of 6 seconds or $185 \mathrm{~m}$ (see Table 1 ). The model domain is $1.30^{\circ}$ $-1.81^{0} \mathrm{~N}$ and $124.46^{\circ}-124.98^{\circ} \mathrm{E}$, as shown in Figure 1.

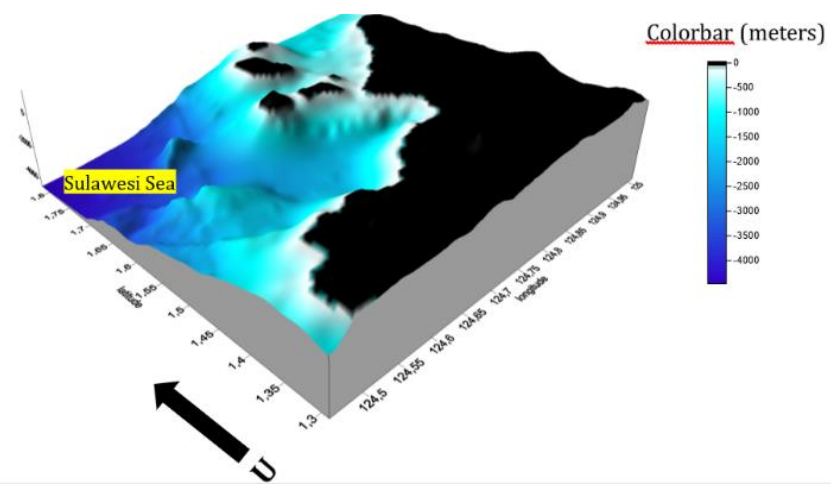

Figure 1. 3D Bathymetry of Manado Bay.

We combined the bathymetry data with the shoreline data to create a grid with $0.002^{0} \times 0.002^{0}$ resolution (Figure 1). The grid for the model is then processed to generate depth data using QUICKIN. The QUICKIN refers to the triangular interpolation method for the grid's uneven size, which has a different resolution from the bathymetry data. An interpolation process is needed to fill the empty grid depths

We divided the study area boundary conditions in the 2D Hydrodynamic DELFT3D-FLOW model into the open and closed boundary conditions. This simulation's two open boundary conditions are the western and northern parts (Figure 2). The model assumes that there is no flow through the closed boundary and the shear stress along the closed boundary has a free-slip condition

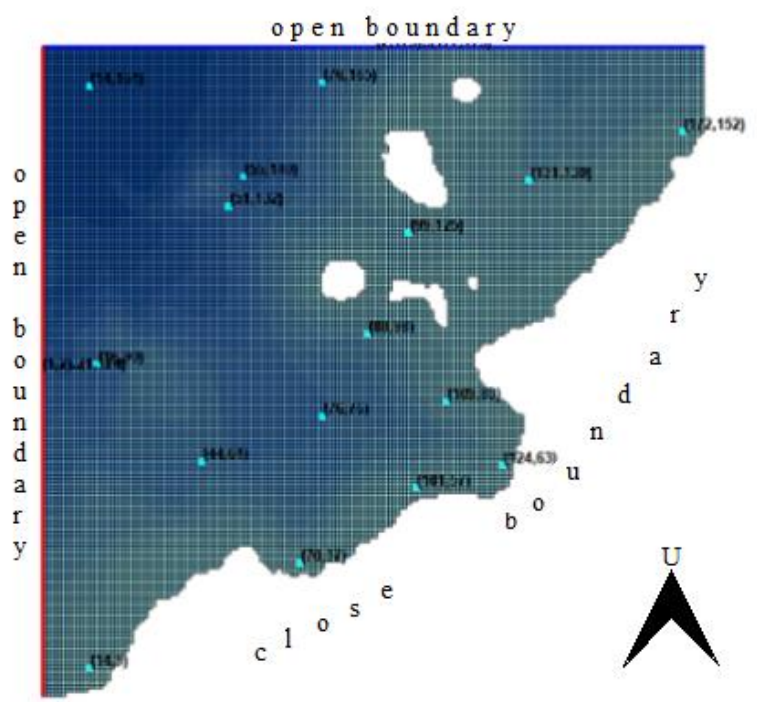

Figure 2. The hydrodynamic model boundary conditions. Blue dots ilustrate random flow observation points. The red and blue lines indicate the west and north open boundary, respectively. The eastern coastline is treated as a closed boundary.

Additionally, the model temperature specifications and heat exchange through the surface are zero. Natural temperature is assumed to be constant through time and space.

\section{Tidal Component}

We use the tide data as the model lateral boundary. The tidal data is extracted from the Tidal Model Driver (TMD) and used as the open boundary's initial data, consisting of tidal amplitude and phase for eight constituents, i.e., M2, $\mathrm{S} 2, \mathrm{~K} 1, \mathrm{O} 1, \mathrm{~N} 2, \mathrm{P} 1, \mathrm{~K} 2$, and Q1. 


\section{Wind Data}

In addition to tides, we also applied wind as model forcing at the surface. We obtained the wind data from the ECMWF at $1.6^{\circ} \mathrm{N}$ and $124.5^{\circ} \mathrm{E}$ that spans from June 2016 to May 2017 (ECMWF, 2019). Wind data is then processed to fit the format required in the DELFT3D-FLOW application. The windrose graph presents the processed wind data to show the seasonal variation (see Figures 3$6)$.

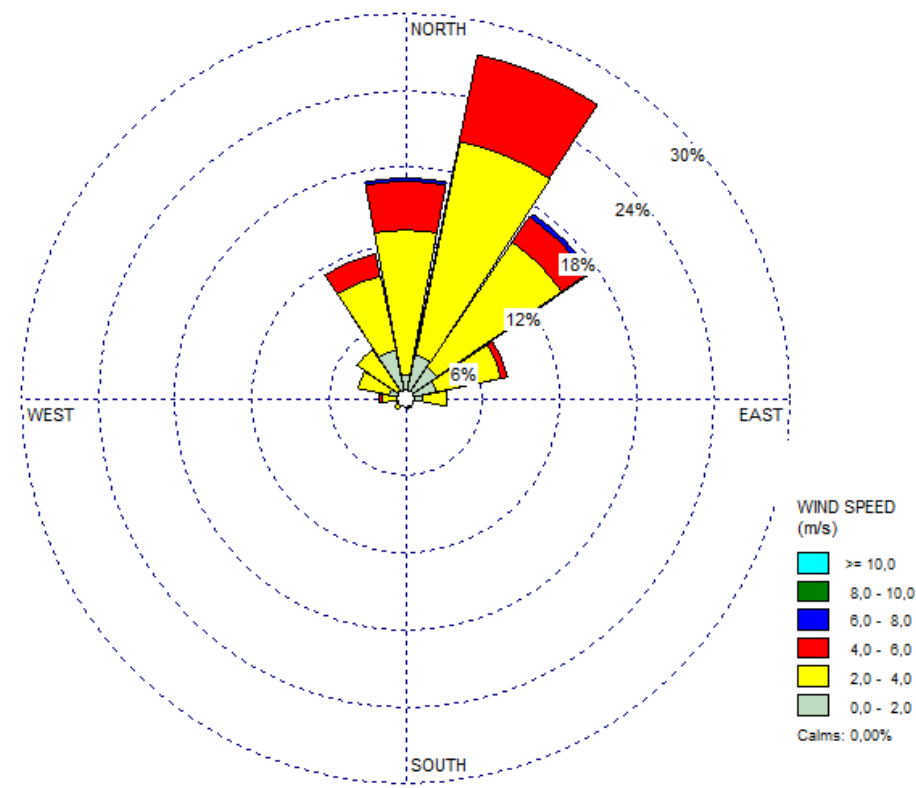

Figure 3. Summer monsoon windrose (June - August 2016)

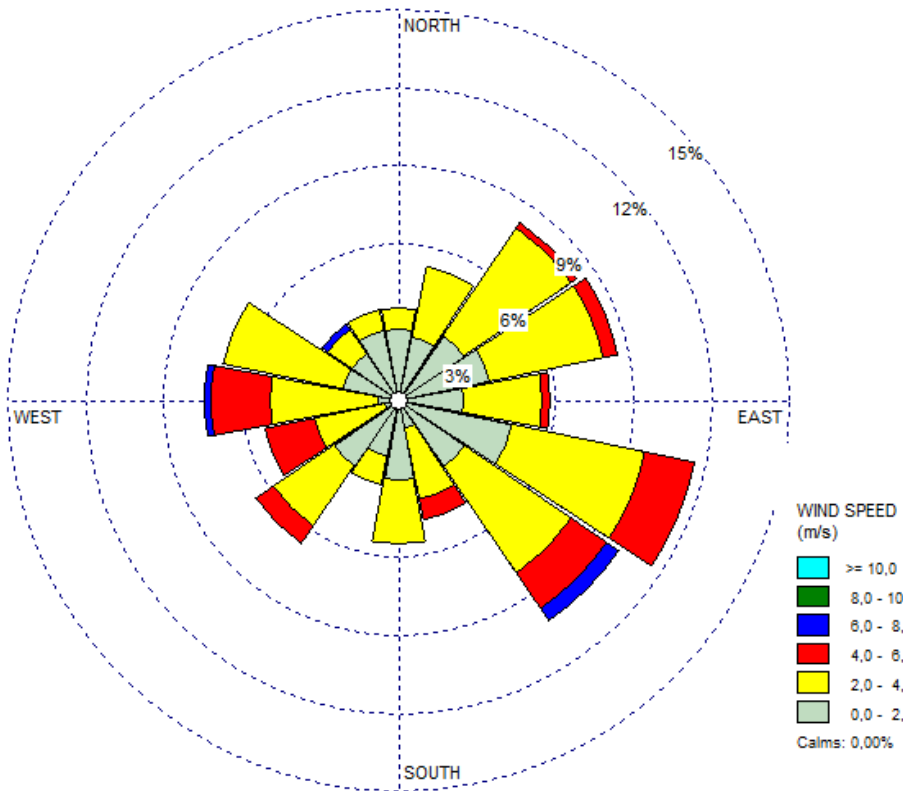

Figure 4. Transitional monsoon 1 windrose (SeptemberNovember 2016)

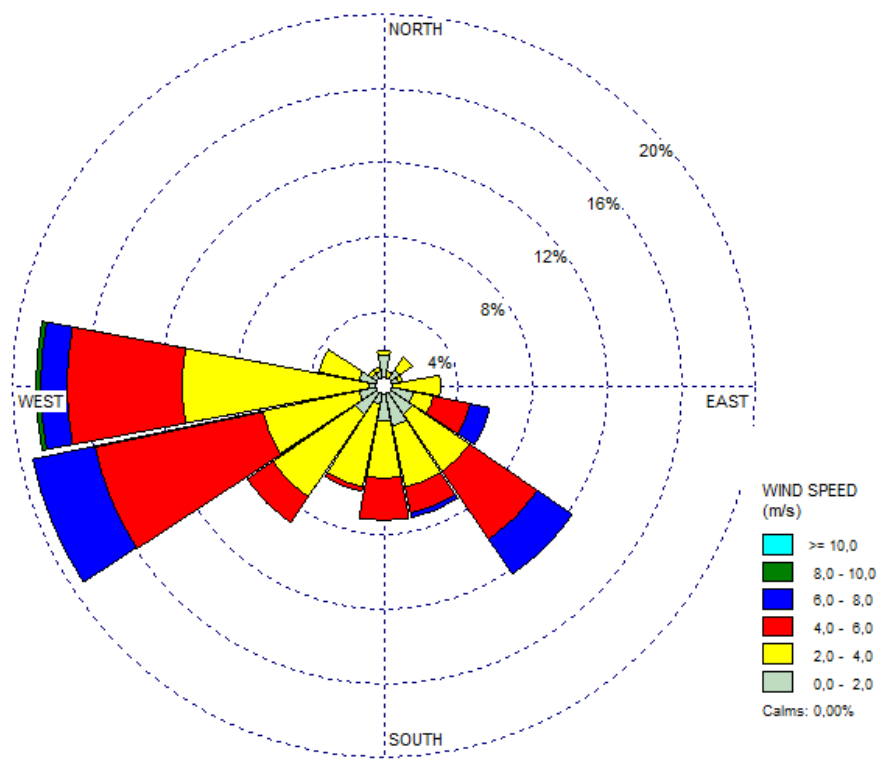

Figure 5. Winter monsoon windrose (December 2016February 2017)

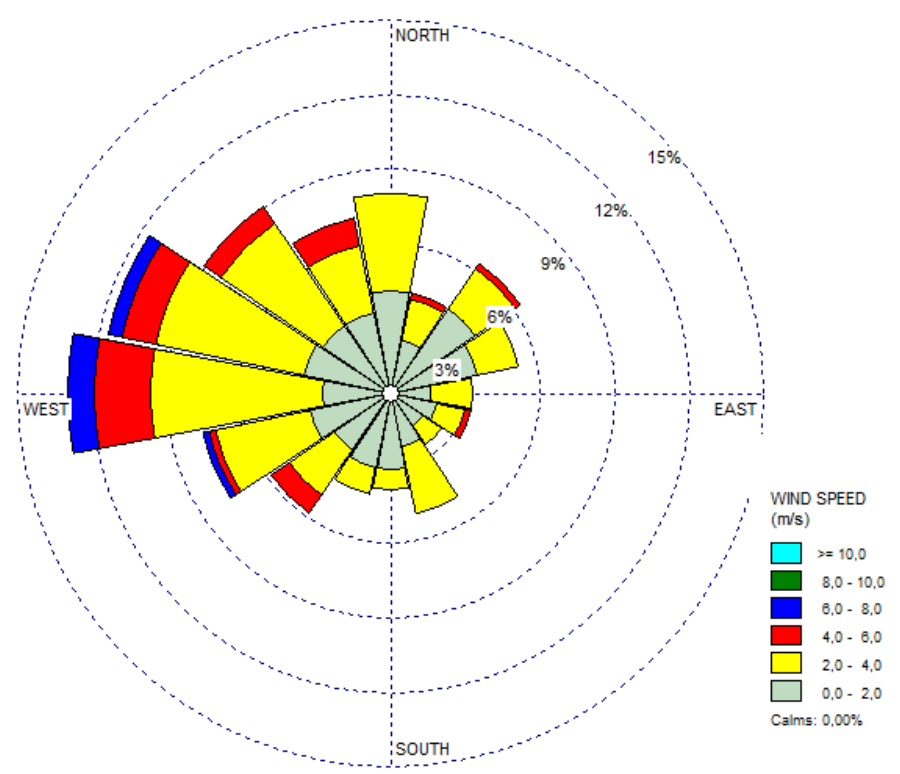

Figure 6. Transitional monsoon 2 windrose (March-May 2017)

Wind speed indicator $(\mathrm{m} / \mathrm{s})$ for Figure $3-6$.

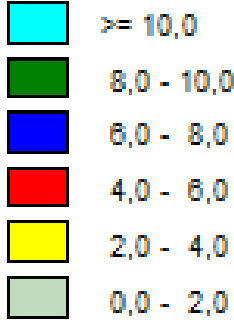

Calms: $0,00 \%$ 


\section{Verification Method}

To verify the model result, we compared the tidal elevation from the simulation with the field measurements. Then, we verified the model quantitatively by calculating the Root Mean Square Error (RMSE) and Mean Absolute Percentage Error (MAPE) as shown in Equations (6) and (7), respectively. MAPE is an accuracy measure of a forecast system.

$$
\begin{aligned}
& \text { RMSE }=\sqrt{\frac{\sum_{i=1}^{N}\left(Z_{f i}-Z_{0 i}\right)^{2}}{N}} \\
& M A P E=\frac{1}{N} \sum_{t=1}^{n} \frac{\left|Z_{f i}-Z_{0 i}\right|}{Z_{f i}} \times 100 \%
\end{aligned}
$$

where,

$Z_{f:}$ elevation data from field measurement

$Z$ : elevation from model

$N$ : the number of data

\section{Result and Discussion}

\section{Model Verification}

The simulated tidal elevation is compared with the Badan Informasi Geospatial (BIG) - Indonesia's Geospatial Information Agency - observation data from 1 to October 29th 2018. We verify the simulated tidal elevation in Manado Station, specifically at $1.49^{\circ} \mathrm{N}$ and $124.84^{\circ} \mathrm{E}$.

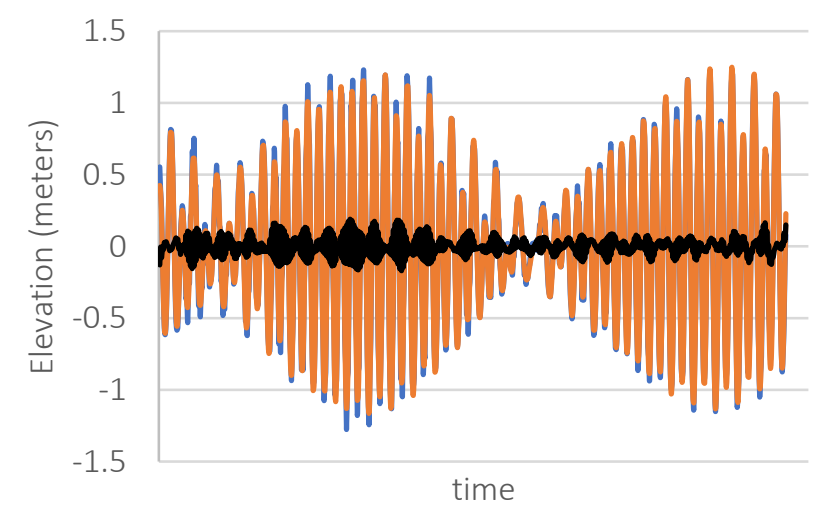

data from simulation models $\longrightarrow$ BIG field measurement $\longrightarrow$ Residual

Figure 7. The comparison of tidal elevation data from simulation with BIG field measurement in the Manado Station from 1 to 29 October 2018.

The comparison of simulated tidal elevation with BIG field measurement shows two floods and two ebbs (Figure 7) with a maximum difference of 0.19 meters. The highest and lowest tidal amplitudes, according to the observation, are 1.17 and -1.31 meters. Furthermore, the highest and lowest tidal amplitudes from the model simulation are 1.22 and -1.27 meters. The simulated amplitudes at the first flood and the second flood are 1.16 meters and 1.22 meters, respectively. Likewise, at the first ebb and the second ebb, the elevation value is different. It could be due to different tidal signal influence that causes the amplitude to increase over a certain period.

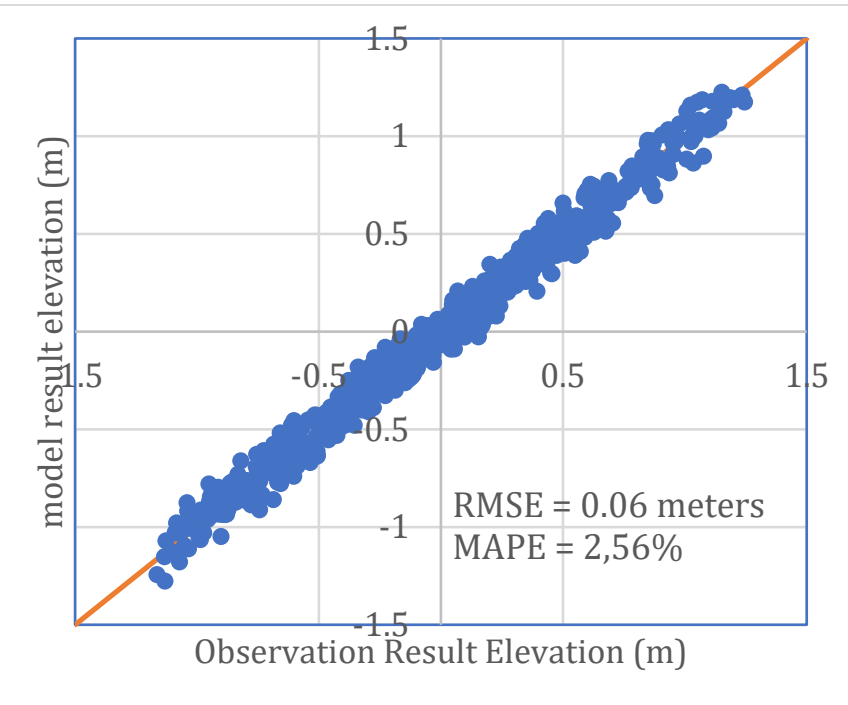

Figure 8. Comparison of simulated tidal elevation and BIG observation data in Manado Station with the red line representing the line $\mathrm{x}=\mathrm{y}$.

Best fit line, RMSE, and MAPE calculations are shown in Figure 8. The RMSE value is 0.06 meters, which indicates that the simulated tidal elevation has a 6 centimeters difference with the measurement. Meanwhile, the MAPE value of $2.56 \%$ shows the deviation value of the simulated tidal elevation from the field measurements. Thus, the accuracy value can be determined by subtracting the total value $(100 \%)$ by the MAPE value, which is about $97.44 \%$. Figure 8 also shows that the model and observation data distribution converge around the 1: 1 line. It indicates that the model results are close to the observations (real conditions). Therefore, MAPE, RMSE, and the best fit line show a good data confidence level. Thus, the model results can be used for further analysis.

\section{Characteristics of Sea Surface Current in Manado Bay}

The following section presents the current conditions to identify how much wind affects the currents around the study area at each tidal cycle (slack before the flood, flood, slack before ebb, and ebb) (Figures 9-16). For details, the simulations were divided into four months, each representing a different season that shows varying current velocity.

During the summer monsoon (Figure 9 and 10), sea surface current generally flows from the northeast. Water mass coming from the Pacific Ocean to the southwest of the Mando Bay with an average speed of 1.1 $\mathrm{cm} \mathrm{s}^{-1}$. The current direction follows the wind direction (Figure 3), which also comes from the northeast. At the deeper area, the current changes insignificantly compared to around the Bay, which is faster, and moves 
back and forth. In general, the current direction during a spring tide (Figure 9) fluctuates from and towards the northeast. Current conditions around the strait of Bunaken National Park $\left(1.57^{\circ}-1.81^{\circ} \mathrm{N}, 124.62^{\circ}\right.$ $124.88^{\circ} \mathrm{E}$ ) are chaotic due to shallower depths and the presence of islands so that the current is deflected and moves faster. This phenomenon is called refraction. When passing through an obstacle like an island, the current tends to spread or what is called diffraction.
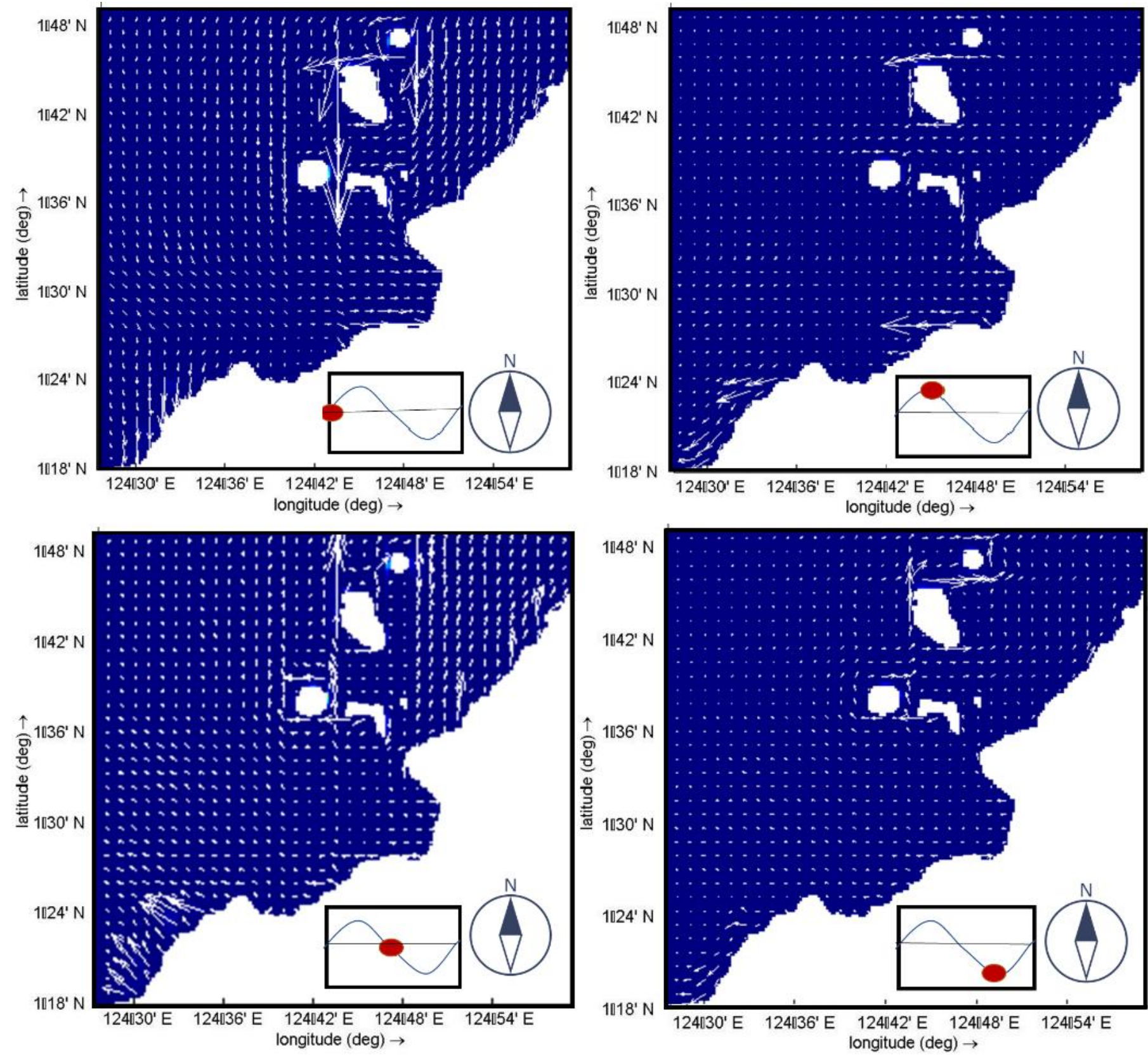

Figure 9. Simulation of current movements in Manado Bay during the spring tide summer monsoon on 22 July 2016.

During neap tide (Figure 10), the current speed along the area with bathymetric changes $\left(1.36^{\circ} \mathrm{N}\right.$ and $\left.124.52^{\circ} \mathrm{E}\right)$ is faster than the other. The current speed when flood and ebb around Bunaken are faster than in slack before flood and slack before ebb. It indicates that wind does not affect current movement at neap tide in the summer monsoon. 

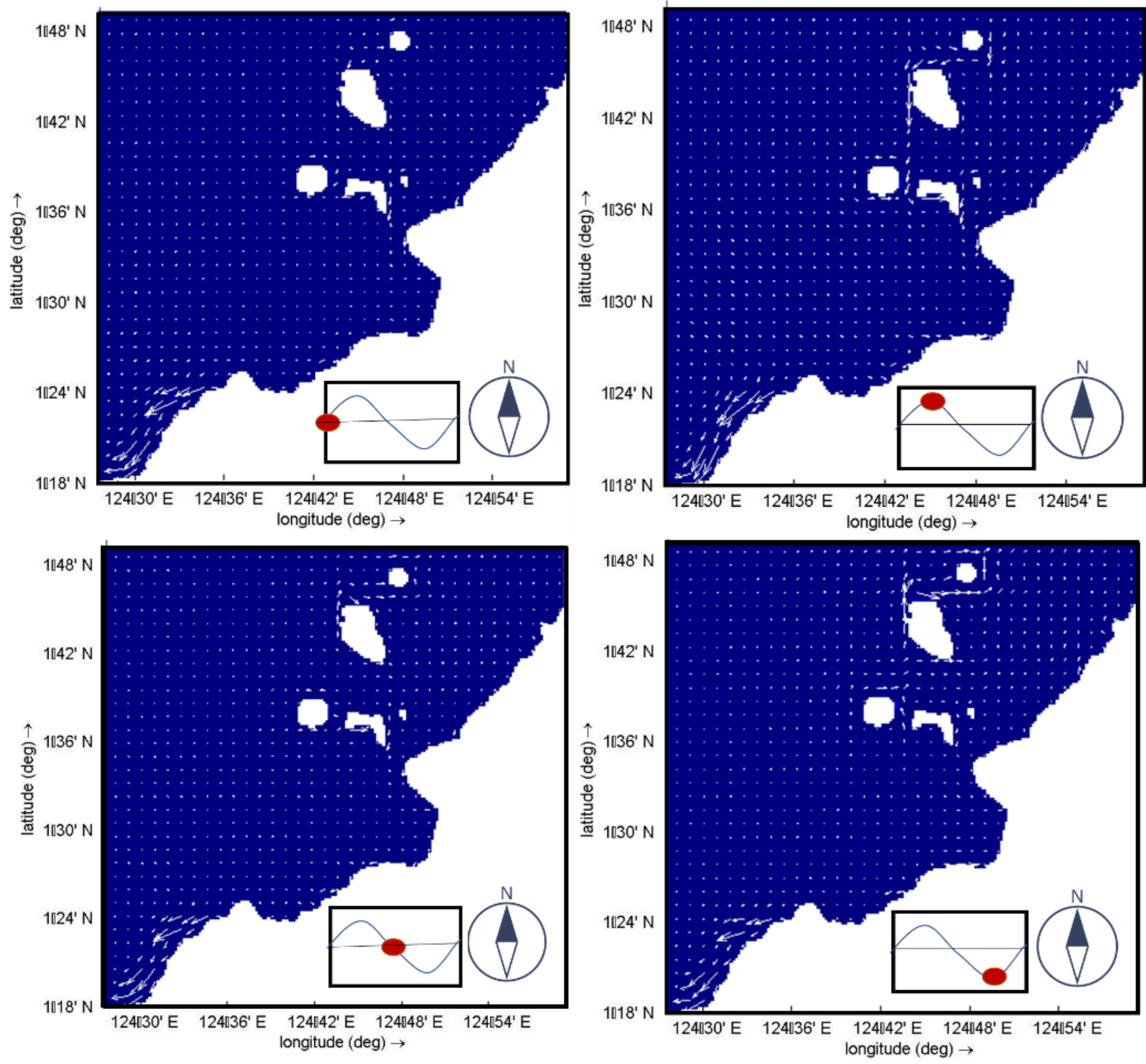

Figure 10. Simulation of current movements in Manado Bay during neap tide in the summer monsoon on 13 July 2016.

On the contrary, during the transition monsoon 1 (Figure 11 and 12), the current flows from the southeast to the northwest, with an average speed of $1.3 \mathrm{~cm} \mathrm{~s}^{-1}$. The current direction corresponds to the wind direction (Figure 4), which also comes from the southeast. During spring tide (Figure 11), current speed when slack before flood and slack before ebb tends to be faster than flood and ebb because it is a transition process of changing the current direction where the water gradient is large, so the current speed becomes fast. In addition, changes in direction on the coast are faster and the currents move back and forth, while the currents that occur in the deeper area tend to rotate.

We found that the current speed during transition monsoon 1 is slower during neap tide than spring tide. The difference velocities of the two tidal conditions is caused by the huge difference in the tidal interval elevation during spring tide and neap tide. The bigger the interval elevation, the stronger the current that will be created. When the spring tide, the moon, earth, and the sun are in line, it causes the moon and sun gravity to reach it maximum. This made the water level rise to the maximum.

In the winter monsoon, the current flows from the southwest to the east with an average speed of $1.9 \mathrm{~cm}$ $\mathrm{s}^{-1}$, as shown in Figures 13 and 14. It is consistent with the wind direction (Figure 5), which also comes from the southwest. The direction of sea surface current changes during the transition monsoon 2 ( Figure 15 and 16). The current flows from west to east with an average speed of $1.5 \mathrm{~cm} \mathrm{~s}^{-1}$. It corresponds to the wind direction (Figure 6), which also comes from the east. The sea surface current speed in the winter monsoon is the largest. It happens because, during the winter monsoon (December 2016 February 2017), La Nina causes the wind speed to increase more than usual. Therefore, the current speed is higher. 

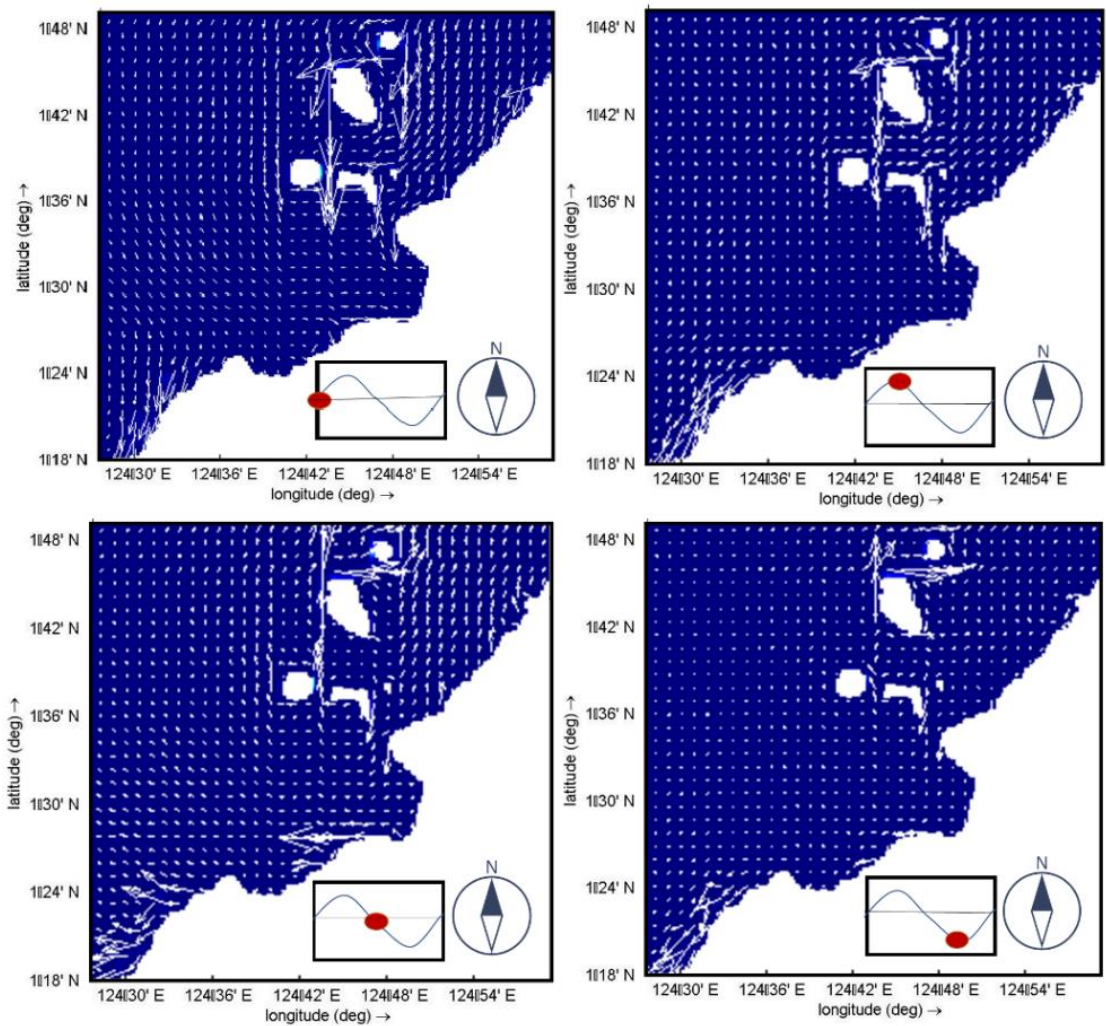

Figure 11. Simulation of current movements in the waters of Manado Bay during spring tide in transitional monsoon 1 on 19 October 2016.
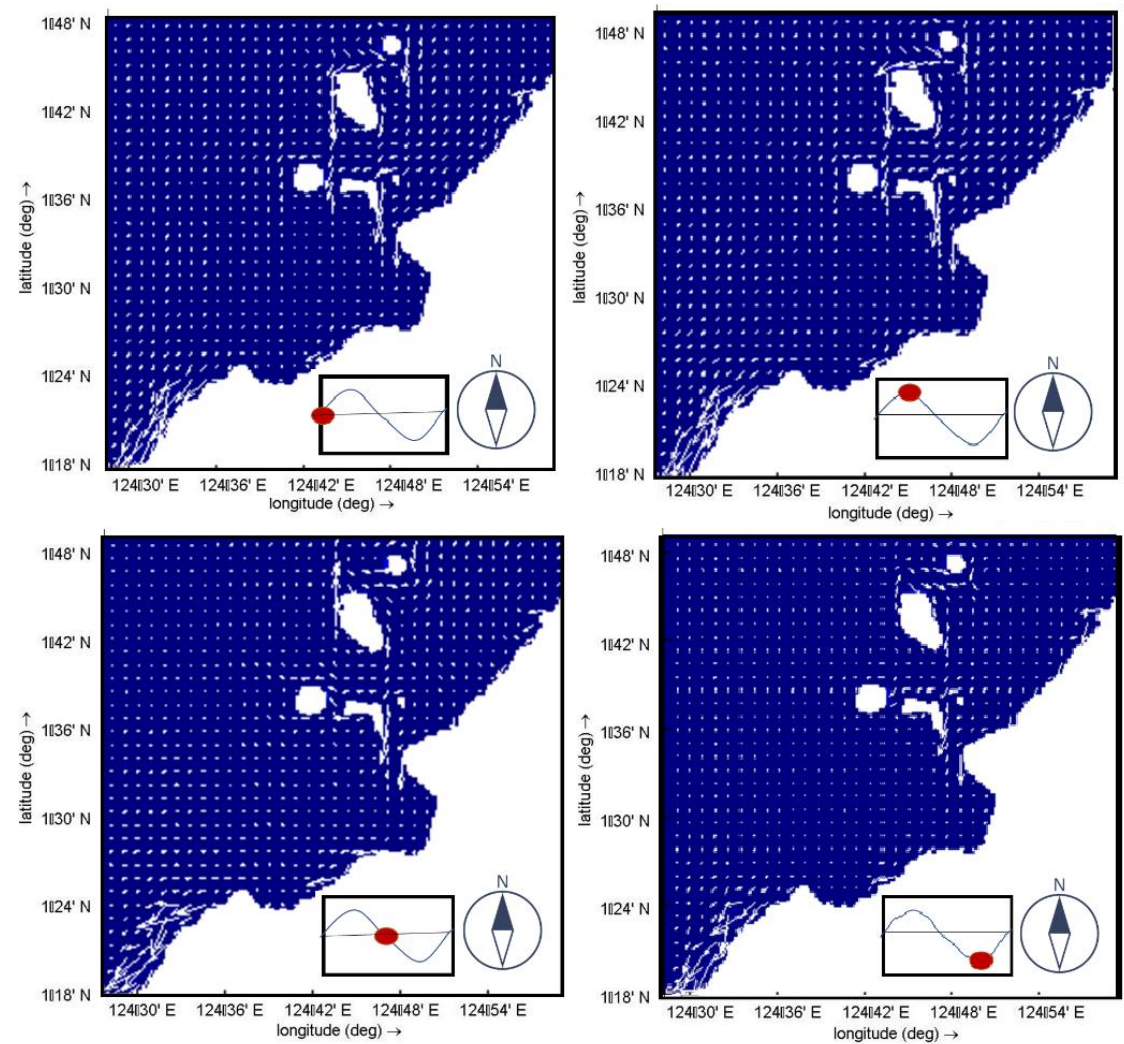

Figure 12. Simulation of current movements in the waters of Manado Bay during neap tide in transitional monsoon 1 on 11 October, 2016. 

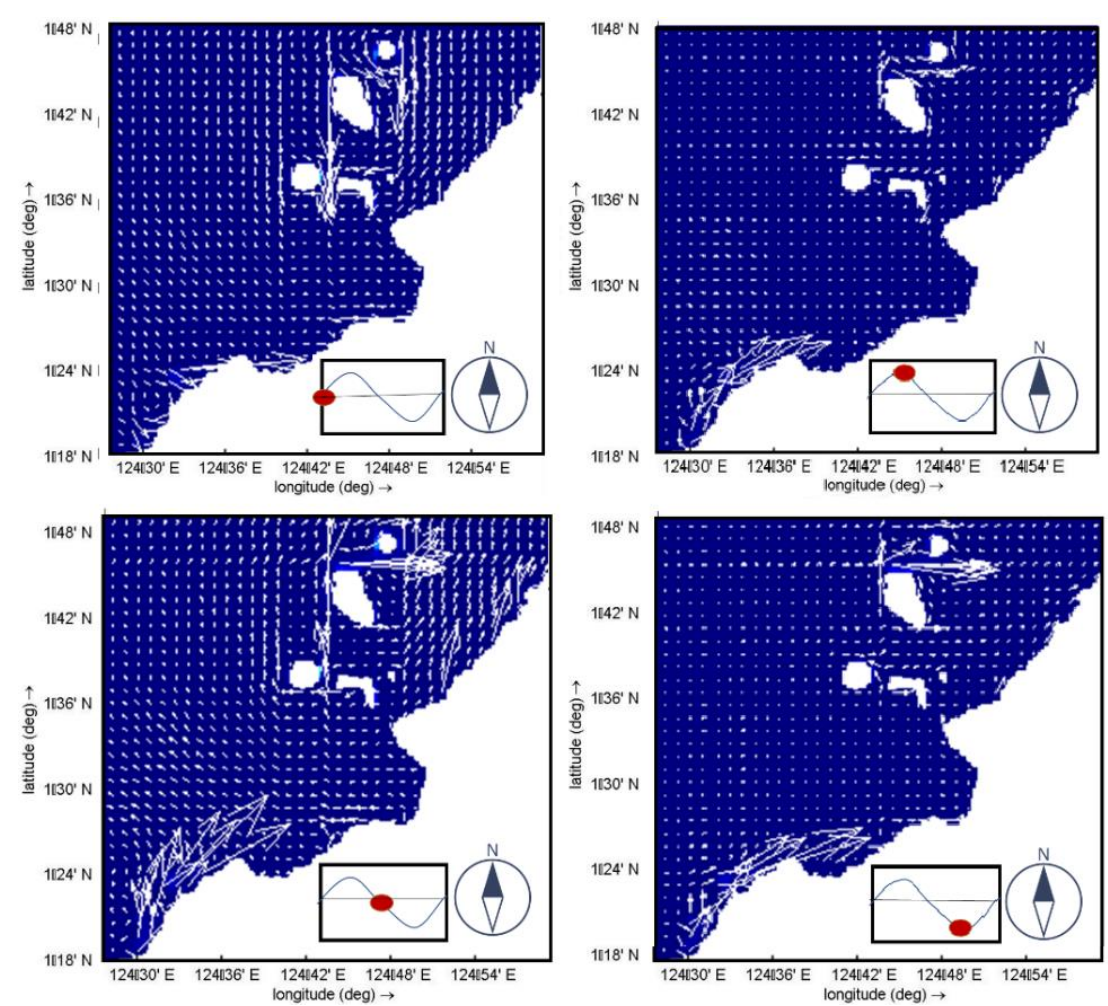

Figure 13. Simulation of current movements in the waters of Manado Bay during spring tide in the winter monsoon on 13 January 2017.
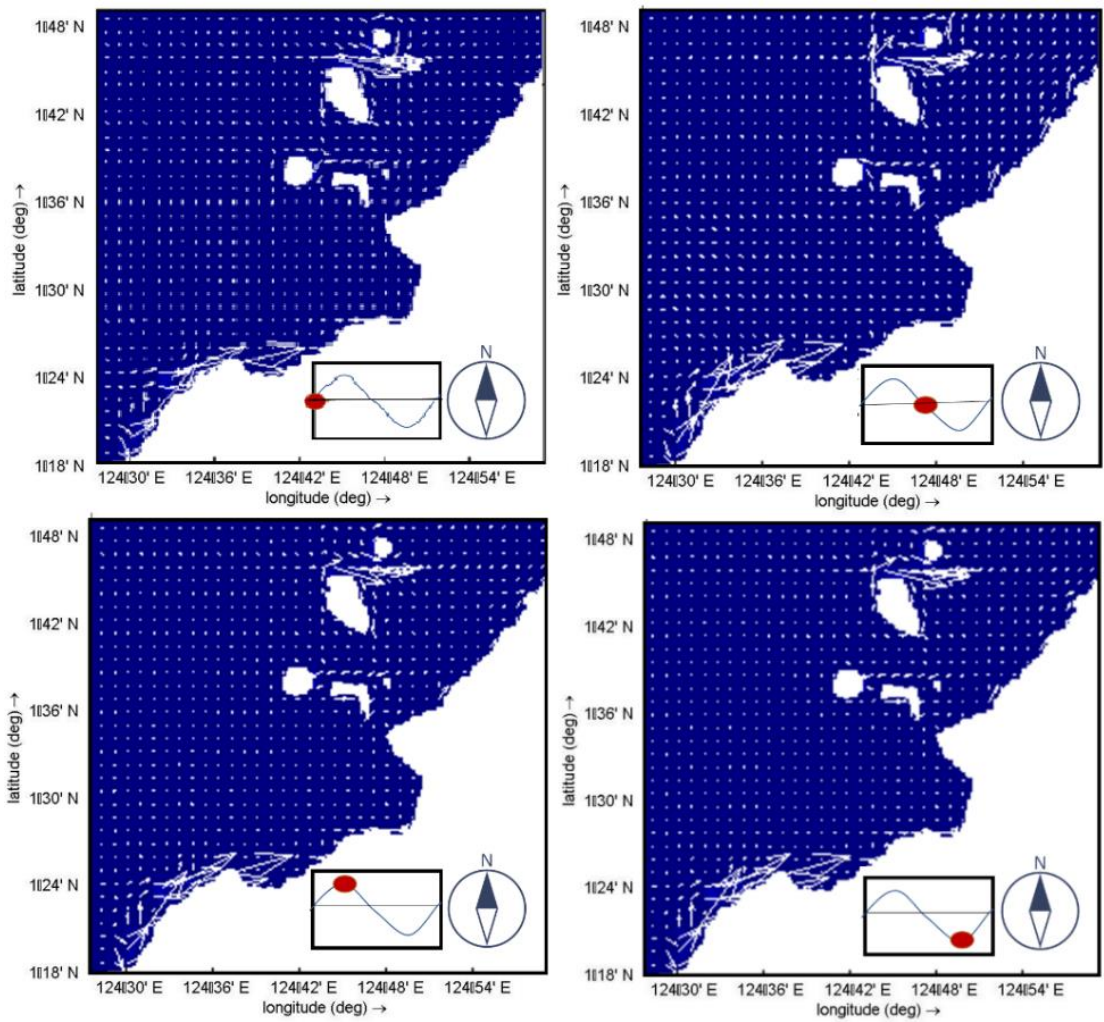

Figure 14. Simulation of current movements in the waters of Manado Bay during neap tide on 6 January 2017. 

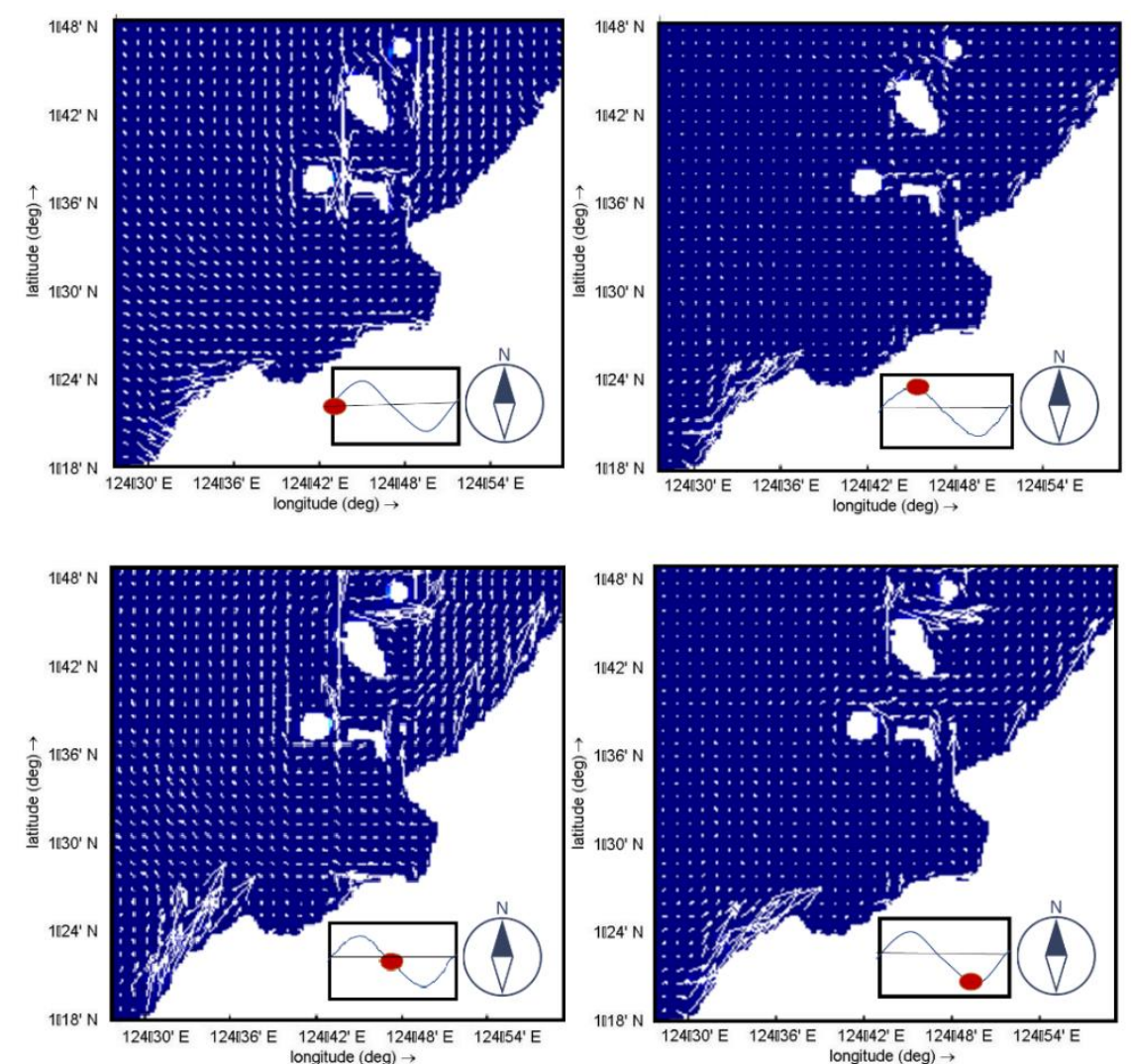

Figure 15. Simulation of current movements in the waters of Manado Bay during spring tide in Transitional monsoon 2 on 12 April 2017.
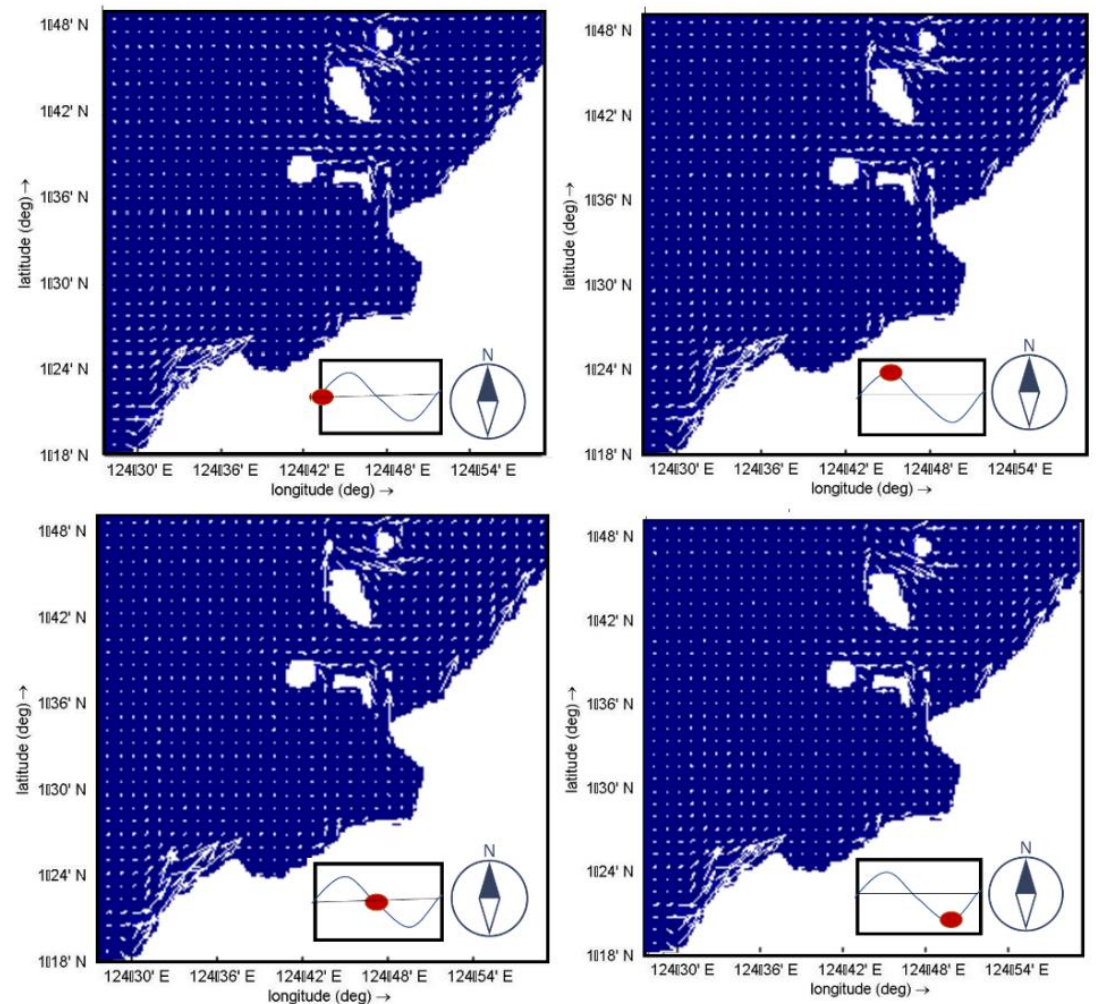

Figure 16. Simulation of current movements in the waters of Manado Bay during neap. 


\section{Conclusion}

The simulated elevation has RMSE and MAPE values of 0.06 meters and $2.56 \%$, respectively, indicating reasonably good results compared with the observation from BIG. The current speed is stronger during spring tide than during neap tide for every season. The current speed in Manado Bay during slack before ebb and slack before flood is faster than during flood and ebb. The current speed increases around the strait of the Bunaken National Park $\left(1.57^{\circ}-1.81^{\circ} \mathrm{N}, 124.62^{\circ}-124.87^{\circ} \mathrm{E}\right)$ due to refraction, diffraction, changes in depth to become shallower, and the presence of islands. Sea surface current movement is influenced by the prevailing wind over the area. The simulation shows that the surface current flows from the northeast to the southwest with an average speed of 1.1 $\mathrm{cm} \mathrm{s} \mathrm{s}^{-1}$ during the summer monsoon. The current originates from the southeast to the northwest with an average speed of $1.3 \mathrm{~cm} \mathrm{~s}^{-1}$ during the transitional monsoon 1. During the winter monsoon, current flows from the southwest to the east with an average speed of $1.9 \mathrm{~cm} \mathrm{~s}^{-1}$. Meanwhile, during the spring monsoon, the current moves from west to east with an average speed of $1.5 \mathrm{~cm} \mathrm{~s}^{-1}$. The knowledge of currents can be used to deterime the marine debris movement in Manado Bay.

\section{Acknowledgement}

This research was supported by the project "Marine Science \& Technology Cooperation between Korea and Indonesia (20180319)" funded by the Ministry of Oceans and Fisheries, Korea.

\section{References}

Ali, M., Mihardja, D.K. \& Hadi, S. (1994). Ocean Tides. Bandung Institute of Technology, Bandung

Dean, R.G., \& Dalrymple, R. A. (1991). Water Wave Mechanics for Engineers and Scientists. World Scientific Publishing Co. Pte. Ltd, Singapore.

Deltares Team (2018). DELFT3D User manual. Delft University of Technology, Delft.

Geyer, W.R. (1997). Influence of wind on dynamics and flushing of shallow estuaries. Estuarine, Coastal and Shelf Science 44 (6): 713722 .

Holthuijsen, L. (2007). Wave in ocean and coastal Waters, Cambridge University Press, New York.

Kalangi, P.N.I. (2000). Surface divergence in Port Phillip Bay. Journal of the Faculty of Fisheries. Unsrat II (1): 34-38.

Knauss, J.A. (1997). Introduction to Physical Oceanography. Prentice Hall, Upper Sadle River.

Lewis, R. (1997). Dispersion in Estuaries and Coastal Waters. Wiley, Chichester

Narahawarin, S. A., Djamaluddin, R., \& Angmalisang, P. (2013). Characteristics Of Coastal Current In Sario Tumpaan Waters-Manado Bay. Journal of Coastal and Tropical Seas.

Radjawane, I. M., \& Hadipoetranto, P.P. (2014). Characteristics of Water Mass in the Branching of Indonesian Trans-Flow in Sangihe Talaud Waters Using 2010 Satal Index data, Journal of Tropical Marine Science and Technology, 6, (2), 525-536.
Tatanging, D.Y., Luasunaung, A., Modaso, V.O., Kalangi, P.N., Masengi, K.W., \& Kumajas, H.J. (2019). Flow of Lagrangian Around Fads of Manado Bay Center. Journal of Capture Fisheries Science and Technology, 26-32.

Wyrtki, K. (1961). Physical oceanography of Southeast Asian waters. Naga report. 